\title{
APLICAÇÃo E ANÁLISE DO ÍNDICE PADRONIZADO DE PRECIPITAÇÃO NO CIRCUITO DAS ÁGUAS PAULISTA
}

SIQUEIRA, Beatriz - biasiqueira@ige.unicamp.br

Instituto de Geociências da Universidade Estadual de Campinas - UNICAMP

NERY, Jonas Teixeira - jonas@ourinhos.unesp.br Universidade do Estado Paulista / UNESP - Ourinhos

\begin{abstract}
RESUMO: O Índice Padronizado de Precipitação (SPI) foi elaborado por Mckee et al. (1993) e consiste em um dos métodos mais utilizados para a quantificação da seca, em diversas escalas de tempo, de modo a caracterizar os diferentes tipos de seca possíveis em dadas regiões. Através do uso do índice de Mckee et al. (1993) objetivou-se quantificar o déficit hídrico na região do Circuito das Águas Paulista, que devido a sua localização, possui grande importância hídrica, econômica e turística no estado de São Paulo. Outro fator que confere extrema significância e objetividade à pesquisa é o fato de a região de estudo estar localizada em uma área atualmente considerada de risco no que diz respeito à estiagem severa que o estado de São Paulo vem sofrendo desde meados do ano de 2013. A finalidade deste trabalho é calcular e analisar os valores de SPI para o Circuito das Águas Paulista, em um período de 6 e 12 meses, de modo a quantificar os maiores e menores índices de seca registrados até então, compreendidos em um período de 42 anos (1970 - 2012).
\end{abstract}

PALAVRAS-CHAVE: variabilidade, déficit de precipitação, riscos, índice.

APPLICATION AND ANALYSIS OF CONTENTS STANDARD OF PRECIPITATION IN THE ÁGUAS PAULISTA'S CIRCUIT

ABSTRACT: The Standardized Precipitation Index (SPI) was drawn up by Mckee et al. (1993) and consists of one of the methods most often used for the quantification of drought, on different time scales, in order to characterize the different types of drought possible in given regions. Through the use of the index of Mckee et al. (1993) the objective of this study was to quantify the water deficit in the region of the circuit Water Paulista, which due to its location, has great importance water, economic and tourism in the state of Sao Paulo. Another factor that gives extreme significance and objectivity to the research is the fact that the study area is located in an area currently considered risk as regards the severe drought that the state of Sao Paulo has been suffering since the middle of the year 2013. The purpose of this work is to calculate and analyze the values of SPI for the circuit of Water Paulista, in a period of 6 and 12 months, in order to quantify the higher and lower levels of drought recorded until then, understood in a period of 42 years (1970 - 2012).

KEYWORDS: variability, deficit of precipitation, risks, index.

\section{INTRODUÇÃO}

As precipitações são variáveis climáticas que podem vir a ocasionar impactos à sociedade, sendo estes, benéficos ou maléficos, de acordo com o grau de intervenção que possam causar em segmentos econômicos, agrícolas e industriais. Não existem muitos estudos que caracterizam o caráter da variabilidade das precipitações no estado de São Paulo, tão pouco na região de estudo desta pesquisa, o Circuito das Águas Paulista. 
De acordo com Schröder (1956) as precipitações são o elemento climático mais importante em uma região situada nos limites dos trópicos. Neste particular deve-se considerar não apenas a distribuição regional, mas, igualmente, a distribuição cronológica. Esta última, determinada pelas estações do ano, é o fator preponderante no planejamento da agricultura, por conseguinte de toda a vida econômica em uma região essencialmente agrícola.

Schröder (1956) afirma que os fatores que influenciam essencialmente a distribuição regional das precipitações no estado de São Paulo são: a) Posição em relação ao sistema circulatório do "alísio sul"; b) Situação no lado oriental de um continente do hemisfério Sul e c) Situação num planalto de 500 a $600 \mathrm{~m}$ de altitude, com leve declive que deságua para o interior do continente e cuja queda íngreme na costa se opõe quase em ângulo reto aos ventos "alísios".

A distribuição sazonal das chuvas é influenciada, sobretudo: a) Pela posição em relação à Zona de Convergência Intertropical (ZCIT), a qual depende da posição anual do sol e b) Pela energia com que, cada vez, a circulação da frente polar sul avança para o norte.

Embora pareça simples a explicação da distribuição das precipitações segundo os cinco itens acima, é bastante complicada a sua análise, visando determinar a parte com que cada componente individual participa da soma total da estrutura genética do curso das precipitações, no estado de São Paulo. Além disso, confrontam-se ainda nessa região do estado os climas mais variados. Isso também dificulta a síntese das precipitações (SCHRÖDER, 1956, p.194)

Em seu estudo sobre a distribuição da precipitação pluvial no estado de São Paulo, Nery (2004) explica que a região Sudeste, onde se localiza o estado de São Paulo, é caracterizada pela atuação de sistemas que associam características de sistemas tropicais com sistemas típicos de latitudes médias e que durante os meses de maior atividade convectiva, a Zona de Convergência do Atlântico Sul (ZCAS) é um dos principais fenômenos que influenciam no regime de chuvas dessas regiões (Quadro e Abreu, 1994).

A Zona de Convergência do Atlântico Sul (ZCAS) pode ser identificada, na composição de imagens de satélite, como uma banda de nebulosidade de orientação nordeste-sudeste (NW/SE), estendendo-se desde o sul da região Amazônica até a região central do Atlântico Sul (Kousky, 1988). Segundo Nery (2013), os mecanismos que originam e mantêm as ZCAS não estão ainda totalmente definidos, porém observações e estudos indicam que é um sistema que sofre influências de fatores remotos e locais. Os primeiros interferem no início e na duração das ZCAS, já os segundos, são determinantes para a ocorrência do fenômeno.

Durante a estação de inverno as regiões serranas do território paulista marcam extremos mínimos de temperatura. No que tange a precipitações, a variabilidade da média anual fica entre 1.500 e 2.000 milímetros (NERY, 1999). 
Os índices pluviométricos exibidos pelo estado de São Paulo variam, desde quotas excepcionalmente altas como aquelas apresentadas pelas encostas da Serra do Mar (2.000 a 4.500 $\mathrm{mm}$ anuais) até chuvas moderados como aqueles que são conhecidos em certos trechos da Depressão Periférica (de 1.000 a $1.100 \mathrm{~mm}$ anuais). No litoral sul do estado, como em trechos limitados do litoral Norte e do extremo noroeste do estado às precipitações giram entre 1.500 e 1.900 mm anuais. Por sua vez a quase totalidade do Planalto Atlântico, assim como o noroeste do estado e áreas na região Centro-Oeste e Oeste-noroeste as precipitações estão compreendidas entre 1.500 e 1.900 mm. (NERY, 2004, p.2-3).

Amaral e Baptista (1997), afirmam que as análises de séries climáticas, dentre elas a da precipitação pluvial, são fundamentais para o planejamento de inúmeras atividades agrícolas, econômicas, sociais, dentre outras estratégicas para o desenvolvimento socioeconômico de um determinado município, região ou estado.

A precipitação pluvial é a responsável pela recarga do potencial hídrico das bacias, essa disponibilidade não ocorre de maneira uniforme em todo território, devido à existência de dinâmicas climatológicas diferenciadas em cada local.

Os regimes pluviométricos estão diretamente relacionados a fenômenos meteorológicos dos quais variam em intensidade, quantidade e frequência, contribuindo para a formação de distintas paisagens e espaços, influenciando assim na interação entre homem e natureza.

Entre os inúmeros elementos climáticos, a pluviosidade se destaca por apresentar interação com outros elementos da sociedade. Seu estudo colabora para as diversas atividades socioeconômicas sobre o espaço, principalmente naquelas que se relacionam a aspectos naturais como solo e a chuva. Nesse sentido, o estudo da precipitação pluvial torna-se relevante no planejamento de atividades agrícolas, visto que as chuvas interferem no preparo do solo e no rendimento das culturas além das necessidades de irrigação.

O uso de índices de chuva que quantifiquem a variabilidade da precipitação vem sendo muito útil, justamente porque promove estimativas do que pode vir a acontecer em diversas situações e locais colaborando assim, para as diferentes atividades socioeconômicas que compõem o espaço geográfico e que estão relacionadas com o solo e com a chuva.

Nesse estudo, o índice utilizado é o Índice Padronizado de Precipitação (SPI), que foi desenvolvido por Mckee et al. (1993) com o objetivo de monitorar e analisar a seca em diferentes escalas de tempo. Esse índice é vantajoso em relação aos demais porque utiliza apenas dados mensais de precipitação, variável monitorada em todas as estações meteorológicas. 


\section{Caracterização da área de estudo}

O Circuito das Águas Paulista (Figura 1) é composto pelos municípios de Águas de Lindóia, Holambra, Amparo, Jaguariúna, Lindóia, Monte Alegre do Sul, Pedreira, Serra Negra e Socorro, localizados na região leste do estado de São Paulo, próximos ao limite sul com o estado de Minas Gerais e também próximos do eixo Campinas-São Paulo, grande mancha urbana responsável individualmente pela maior parte da renda e do consumo do país (FUINI, 2010).

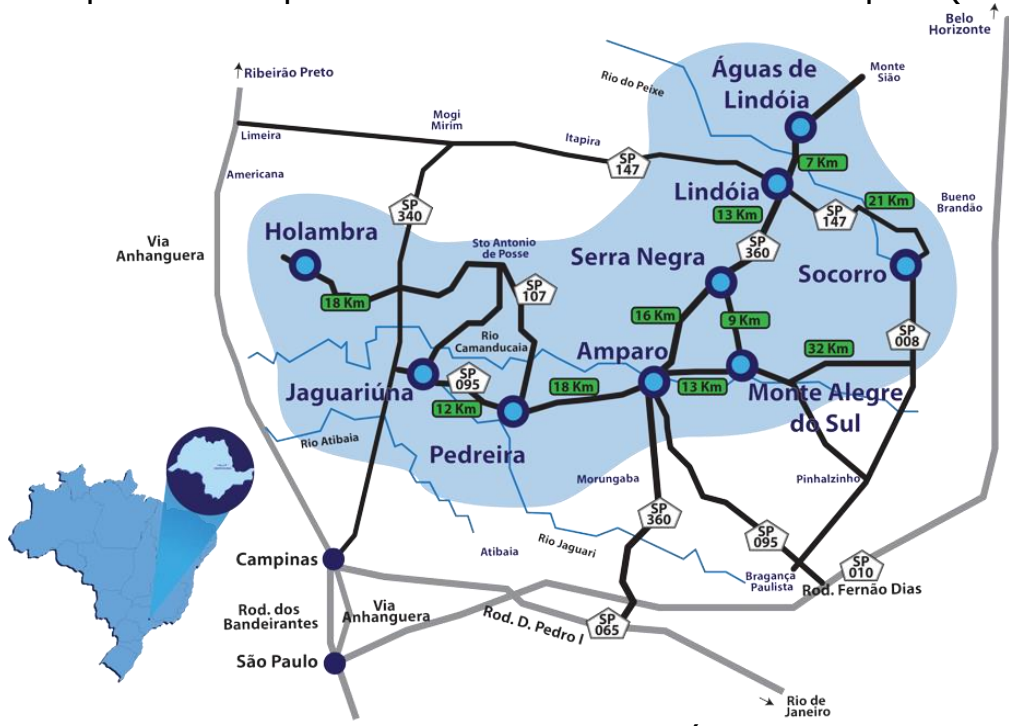

Figura 1: Localização do Circuito das Águas Paulista.

Fonte: http://www.circuitodasaguaspaulista.sp.gov.br/

O município de Jaguariúna, no oeste do Circuito das Águas Paulista, está localizado a 130 quilômetros de São Paulo, capital e a menos de 15 quilômetros de Campinas. Todos os municípios que compõem o Circuito das Águas estão localizados na mesorregião de Campinas (FUINI, 2010).

Todos os municípios que compõem o Circuito das Águas Paulista estão localizados nos vales e montanhas da Serra da Mantiqueira (Domínio do Planalto Cristalino de Mares de morros), e possuem clima ameno (tropical de altitude), propício ao turismo na estação do inverno. Os rios e as bacias hidrográficas que cortam a região são um episódio a parte, pois possuem fontes de água com propriedades medicinais, fato que favorece o turismo hidroterápico em estâncias hidrominerais, essencialmente em Águas de Lindóia, Amparo, Lindóia, Monte Alegre do Sul e Socorro.

No que diz respeito à hidrografia e vegetação, o Circuito é cortado pelo rio Mojiguaçu, rio do Peixe e rio Jaguari. A vegetação é preservada e conta com belas cachoeiras, outro adendo que intensifica o turismo na região abrindo espaço para atividades de aventura como a prática de esportes radicais.

A região de estudo também é referência na hotelaria e turismo do estado de São Paulo. Águas de Lindóia, por exemplo, oferece extrema diversidade no quesito hospedagem e lazer, conta com muitos hotéis e ficou conhecida como um dos mais importantes centros hidroclimáticos do mundo, com o turismo 
voltado para a cura e o repouso. Com área de $55 \mathrm{~km}^{2}$ de montes e vales em meio a Serra da Mantiqueira, uma altitude de aproximadamente 954 metros, Águas de Lindóia possui, em média, 7 mil leitos com salões para receber eventos, congressos e feiras. É a "Capital Brasileira do Termalismo".

Em sua tese Manifestações da governança territorial no Brasil: uma análise do "Circuito das Águas Paulista e do "Circuito das malhas do sul de Minas", Fuini (2010) explica que além dos aspectos que caracterizam a unidade paisagística do Circuito, identifica-se também uma clara divisão do trabalho interna ao conglomerado de municípios (divisão intrarregional do trabalho), destacando as diferenças quanto às atividades econômicas desenvolvidas por cada cidade e seus produtos totais e relativos.

O autor completa afirmando que, sendo assim, as disparidades econômicas e demográficas regionais aparecem de maneira mais clara:

Jaguariúna, por exemplo, é um município com população relativamente modesta, apenas 40.066 habitantes, mas apresenta renda anual superior a três bilhões de reais, graças à arrecadação obtida com a operação de grandes empresas, algumas de natureza multinacional ou transnacional, como a Ambev (ramo de bebidas, antiga Antarctica), belgo-brasileira e a Motorola (ramo de telecomunicações), norte-americana. Já Lindóia, comparativamente, é um pequeno município com apenas 5.924 habitantes e detentor de uma renda anual de pouco mais de cinquenta e três milhões de reais, ou seja, possui renda correspondente a apenas $1,7 \%$ do produto de Jaguariúna (FUINI, 2010, p. 88).

Quanto à população, a região é formada, sobretudo por pequenos municípios em um considerável intervalo de tamanho (de 5.924 em Lindóia até 65.466 em Amparo), com população predominantemente urbana, média aproximada de $80,3 \%$. Entretanto, o grau de urbanização ainda é menor que o do estado (93,4 \%) e da região administrativa de Campinas (92,8 \%). Quanto à condição social, todos os municípios do Circuito das Águas encontram-se no patamar de IDH elevado e Índice de Gini intermediário - que mensura a distribuição de riqueza - além de apresentar incidência de pobreza na população em torno de 14,8 \% (FUINI, 2010).

\section{MATERIAL E MÉTODO}

Para esse estudo, compreendido entre os anos de 1970 a 2012, utilizouse séries de dados pluviométricos de estações meteorológicas distribuídas na região do Circuito das Águas Paulista. Ao todo, soma-se 9 estações (Figura 2) obtidas pela Agência Nacional de Águas (ANA), através de seu site HIDROWEB. Procurou-se obedecer a ordem cronológica dos municípios que compõem o Circuito, no entanto os municípios de Águas de Lindóia e Holambra não apresentaram estações com dados consistentes, sendo assim, uma estação localizada na cidade de Itapira tomou lugar a de Águas de Lindóia, devido à proximidade dos dois municípios e uma outra, nos arredores de Holambra, para representar a mesma. Os dados foram organizados em formato "diário", no Microsoft Excel para o posterior desenvolvimento e análise das isolinhas de precipitação, elaboradas no software Golden Surfer 10. 


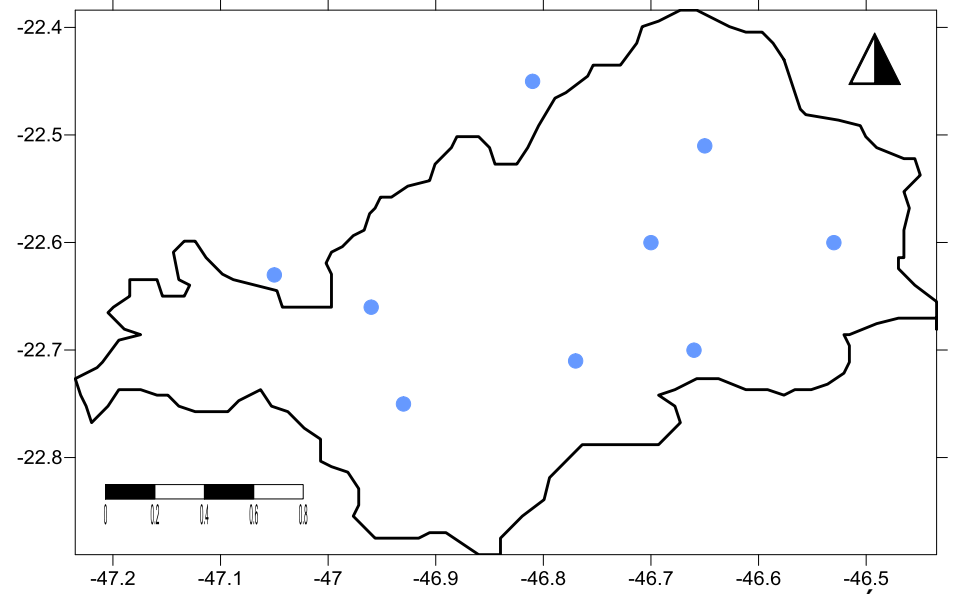

Figura 2: Mapa com a localização das estações do Circuito das Águas Paulista.

Os valores do Índice Padronizado de Precipitação (SPI), foram calculados no software $R$, através da função precintcon.spi.analysis, elaborada por Povoa (2014), onde existem diversos parâmetros de entrada como o objeto a ser analisado, o período que se quer trabalhar, onde deve constar o número de meses a serem agrupados durante o cálculo do SPI.

Após o cálculo e análise dos valores de SPI, obtidos através do software $R$, estes foram organizados em planilhas no Microsoft Excel, para a elaboração dos mapas de isolinhas no software Golden Surfer 10, para os anos de 1983, 1985 e 2009 e 2011.

De acordo com Sansigolo (2004), o SPI é calculado e determinado a partir das funções de densidade de probabilidade que descrevem as séries históricas de precipitação em diferentes escalas de tempo (3, 6, 9, 12 e 24 meses). Quando a função de distribuição da probabilidade já foi ajustada, a chance de certa quantidade de precipitação observada é obtida e o SPI é então computado através da distribuição inversa (McKee et al. 1995).

O índice de seca conhecido por SPI (em inglês, Standardized Precipitation Index) vem sendo usado em vários estudos, devido sua capacidade de quantificar o déficit ou excesso de precipitação em diversas escalas temporais e permitir comparações entre regiões com diferentes características climáticas. Assim, diversos trabalhos científicos têm demonstrado o seu potencial no monitoramento do fenômeno das secas.

O cálculo do SPI requer dados pluviométricos, com no mínimo 30 anos. É determinado a partir da densidade de probabilidade, que descrevem as séries históricas de precipitação nas diferentes escalas de tempo. Foram consideradas as distribuições estatísticas (Normal e Gama), para fins de ajustar uma dada distribuição de freqüência ao total precipitado em uma dada série pluviométrica. A função distribuição de probabilidade Gama é dada por: 


$$
g(x)=\frac{1}{\beta^{a} \varsigma(a)} x^{a-1} e^{\frac{-x}{b}}
$$

Em que $a>0$ é o parâmetro de forma; $b>0$ é o parâmetro de escala e $x>0$ é a quantidade de chuva precipitada. A função Gama é dada por:

$$
\varsigma(a)=\int_{0}^{\infty} y^{a-1} e^{-y} d y
$$

Os parâmetros $a$ e $b$ da função densidade de probabilidade Gama são estimados para cada estação e escala de tempo de interesse. Para estimar os parâmetros $a$ e $b$, utilizam-se as soluções de Máxima Verossimilhança, em que:

$$
\hat{a}=\frac{1}{4 A}\left(1+\sqrt{1+\frac{4 A}{3}}\right)
$$

$$
A=\ln (\bar{x})-\frac{\sum_{i}^{n} x_{i}}{n}
$$

$\hat{b}=\frac{\bar{x}}{\hat{a}}$ de chuva.

$N$ é o número de observações da amostra e $\bar{x}$ é o valor médio dos dados

A função acumulada de probabilidade Gama é:

$G(x)=\frac{1}{\varsigma(\hat{a})} \int_{0}^{x} t^{\hat{a}-1} e^{-t} d t$

A função Gama $\varsigma(a)$ não é definida para $x=0$, mas como a amostra dos dados de precipitação pode conter zeros, a probabilidade acumulada é dada da seguinte forma:

$$
H(x)=q+(1-q) G(x)
$$

Em que $q$ é a probabilidade de ocorrer um zero. Se $m$ for um número de zeros em uma série de precipitação, então $q=m / n$. Segundo Abramowitz e Stegun (1965), a relação entre as distribuições de probabilidade Gama e Normal é dada por:

$$
\begin{array}{ll}
Z=S P I=-\left(t-\frac{c_{o}+c_{1} t+c_{2} t^{2}}{1+d_{1} t+d_{2} t^{2}+d_{3} t^{3}}\right. & 0,0<H(x) \leq 0,5 \\
Z=S P I=+t-\frac{c_{o}+c_{1} t+c_{2} t^{2}}{1+d_{1} t+d_{2} t^{2}+d_{3} t^{3}} & 0,5<H(x) \leq 1,0 \\
t=\sqrt{\ln \left(\frac{1}{(H(x))^{2}}\right)} & 0,0<H(x) \leq 0,5 \\
t=\sqrt{\ln \left(\frac{1}{(1-H(x))^{2}}\right)} & 0.5<H(x) \leq 1.0
\end{array}
$$


Sendo, $\quad c_{o}=2,515 ; \quad c_{1}=0,803 ; \quad c 2=0,010 ; \quad d_{1}=1,433 ; \quad d_{2}=0,189 ;$ $d 3=0,001$.

O cálculo do SPI inicia-se com o ajuste da função densidade de probabilidade Gama às séries de totais mensais precipitados. Em seguida, a probabilidade acumulada de ocorrência de cada total mensal é estimada. A função Normal e inversa Gaussiana é aplicada a essa probabilidade resultando no valor de SPI. O evento seca inicia-se quando SPI torna-se negativo e atinge o valor -1 e finda quando este volta a apresentar valores positivos. Dentro de sua escala, os valores menores ou iguais a -2 indicam "seca extrema" e os maiores ou iguais a +2 indicam "umidade extrema" (Tabela1).

Tabela 1. Classificação do Índice de Precipitação

\begin{tabular}{ll}
\hline SPI & \multicolumn{1}{c}{ Classificação } \\
\hline 2,00 & Extremamente úmido \\
1,00 a 1,99 & Muito úmido \\
0,50 a 0,99 & Moderadamente úmido \\
0,49 a $-0,49$ & Próximo ao normal \\
$-0,50$ a $-0,99$ & Moderadamente seco \\
$-1,00$ a $-1,99$ & Muito seco \\
$\leq-2,00$ & Extremamente seco \\
\hline
\end{tabular}

Fonte: Embrapa Arroz e Feijão, 2009

\section{RESULTADOS E DISCUSSÃO}

O ano de 1983 foi muito úmido em todo o estado de São Paulo, devido a atuação do fenômeno El Niño - Oscilação Sul. Quando o fenômeno ocorre no verão, o aumento acima do normal das temperaturas favorece a formação de nuvens e a consequente ocorrência de precipitação intensa como grandes temporais e enchentes, principalmente nas grandes cidades como São Paulo.

As figuras (Figuras 3 e 4) retratam os valores de SPI encontrados para a região do Circuito das Águas Paulista de 1970 a 2012, em duas escalas de tempo distintas, 6 (Figura 3) e 12 meses (Figura 4). 


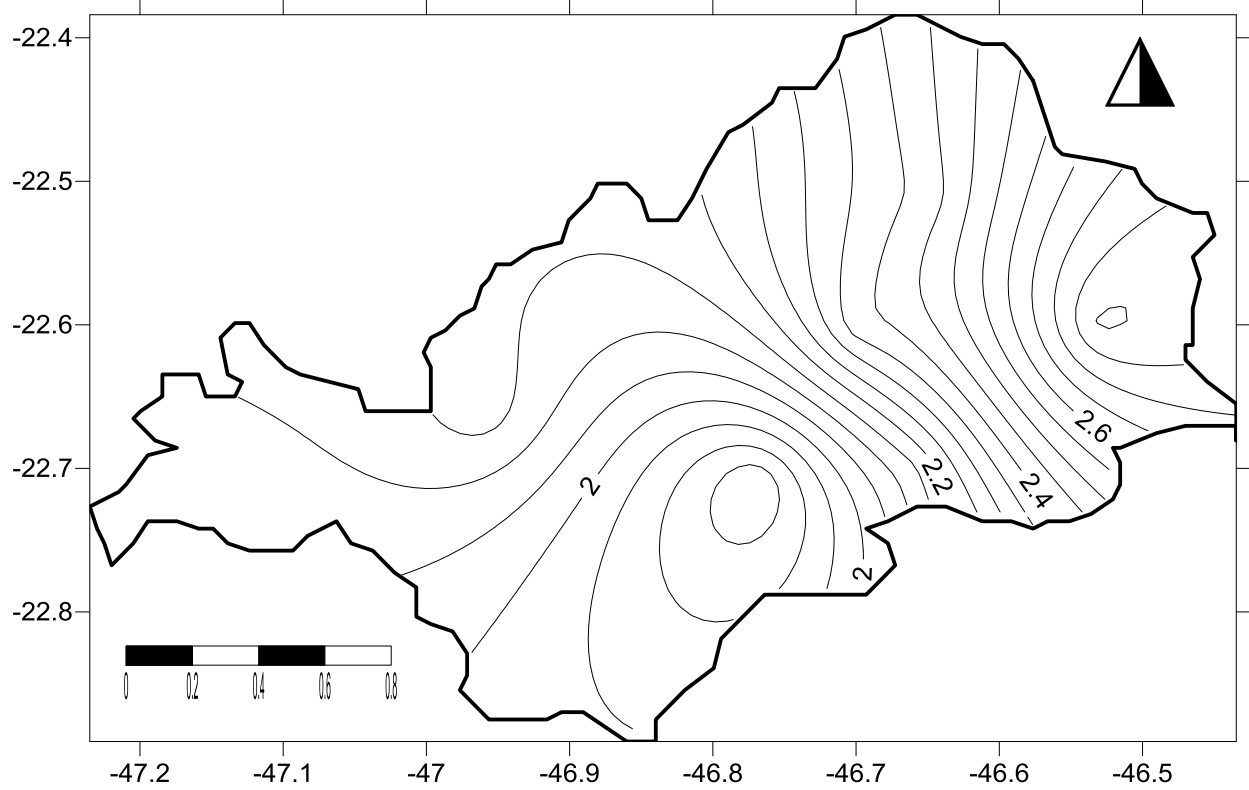

Figura 3: Mapa de distribuição dos valores do SPI, em uma escala de 6 meses, para o Circuito das Águas Paulista, em 1983.

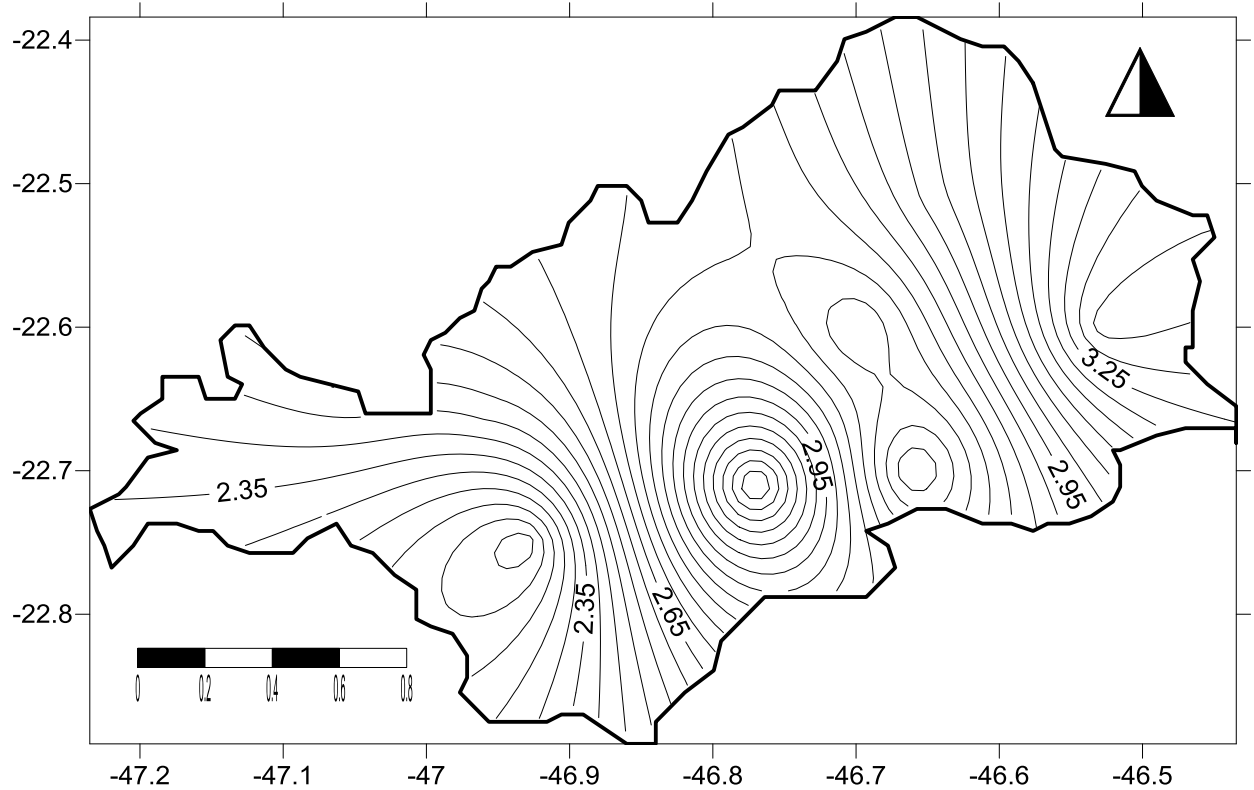

Figura 4: Mapa de distribuição dos valores do SPI, em uma escala de 12 meses, para o Circuito das Águas Paulista, em 1983.

É possível observar valores altos para o índice nas duas escalas de tempo. Em 6 meses, o SPI vai de 2,0 a 2,6; em 12 meses, os valores ficam entre 2,4 e 3,3. De acordo com a Tabela 1, de Fernandes et. al (2009), o ano de 1983 caracteriza-se como extremamente úmido em ambas as escalas de tempo analisadas, no entanto na escala de 12 meses, o comportamento das isolinhas é mais padronizado e intenso, indicando alta concentração de precipitação para o período. 
Também foi analisado o 1985 (Figuras 5 e 6): ano de ocorrência do La Niña, no entanto de baixa intensidade, segundo tabela do Centro de Previsão de Tempo e Estudos Climáticos, o CPTEC.

No Circuito das Águas Paulista, ao contrário da grande maioria do estado de São Paulo, o anos de 1985 não foi tão seco na escala de tempo de 6 meses (Figura 5), já que, foram encontrados valores negativos de SPI até -0,5, ou seja, próximo do normal. Na escala de tempo de 12 meses, os valores de SPI não se apresentam de maneira muito distinta da escala de 6 meses, concentrando-se entre $-0,3$ e - - , , , o que ainda indica a proximidade com a normal esperada para a região. Pode-se constatar então, uma variação para os extremos e déficits de precipitação neste ano, que podem estar atribuídas a variações sazonais da própria região estudada.

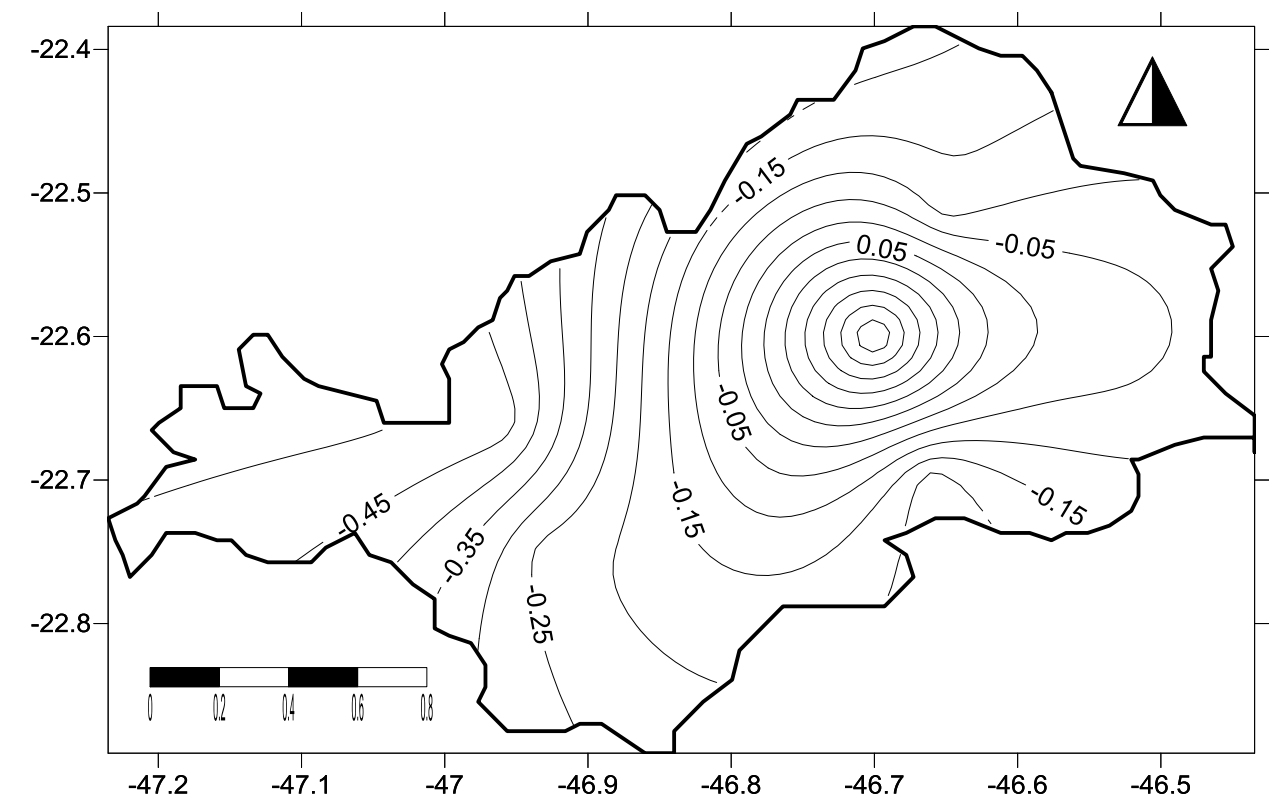

Figura 5: Mapa de distribuição dos valores do SPI, em uma escala de 6 meses, para o Circuito das Águas Paulista, em 1985. 


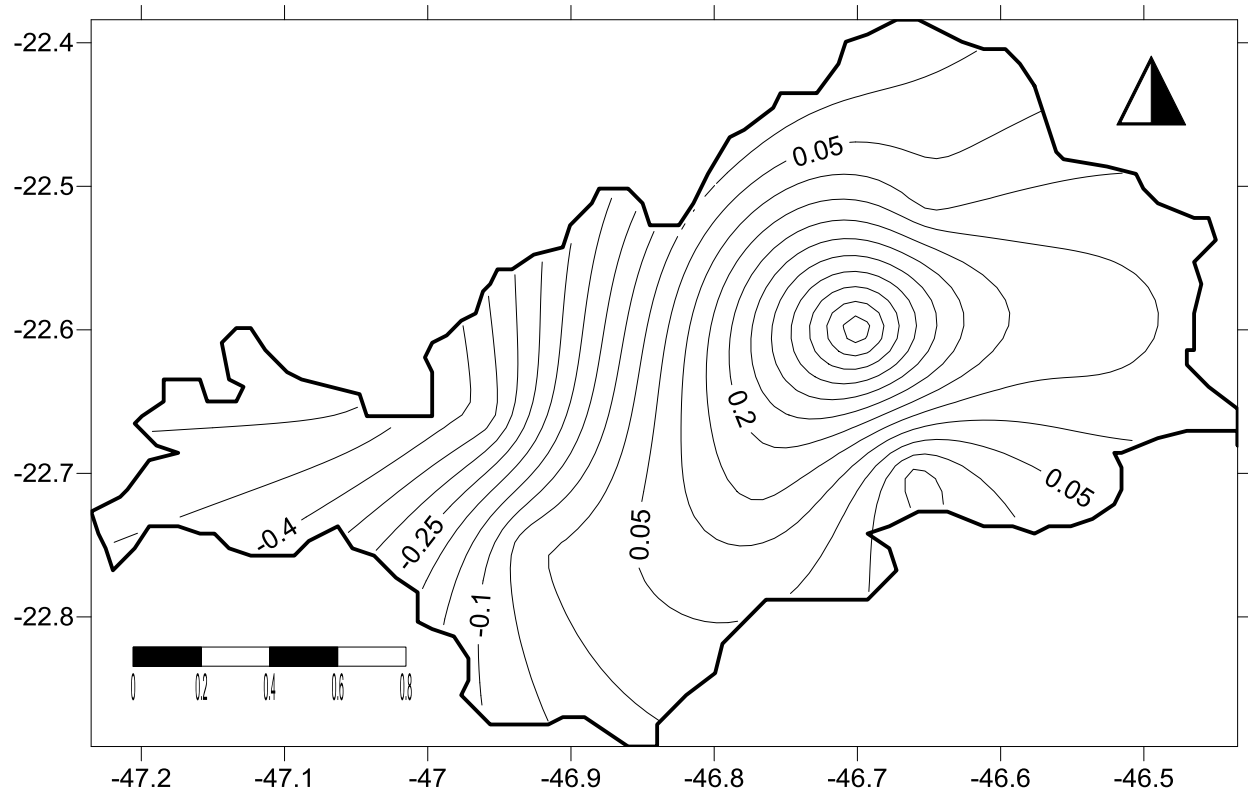

Figura 6: Mapa de distribuição dos valores do SPI, em uma escala de 12 meses, para o Circuito das Águas Paulista, em 1985.

Em 2009, em uma escala de 6 meses (Figura 7), os valores encontrados para o SPI estão entre 0,9 e 1,2, o que, de acordo com a Tabela de Fernandes et al. (2009) caracteriza o ano de muito úmido a extremamente úmido.

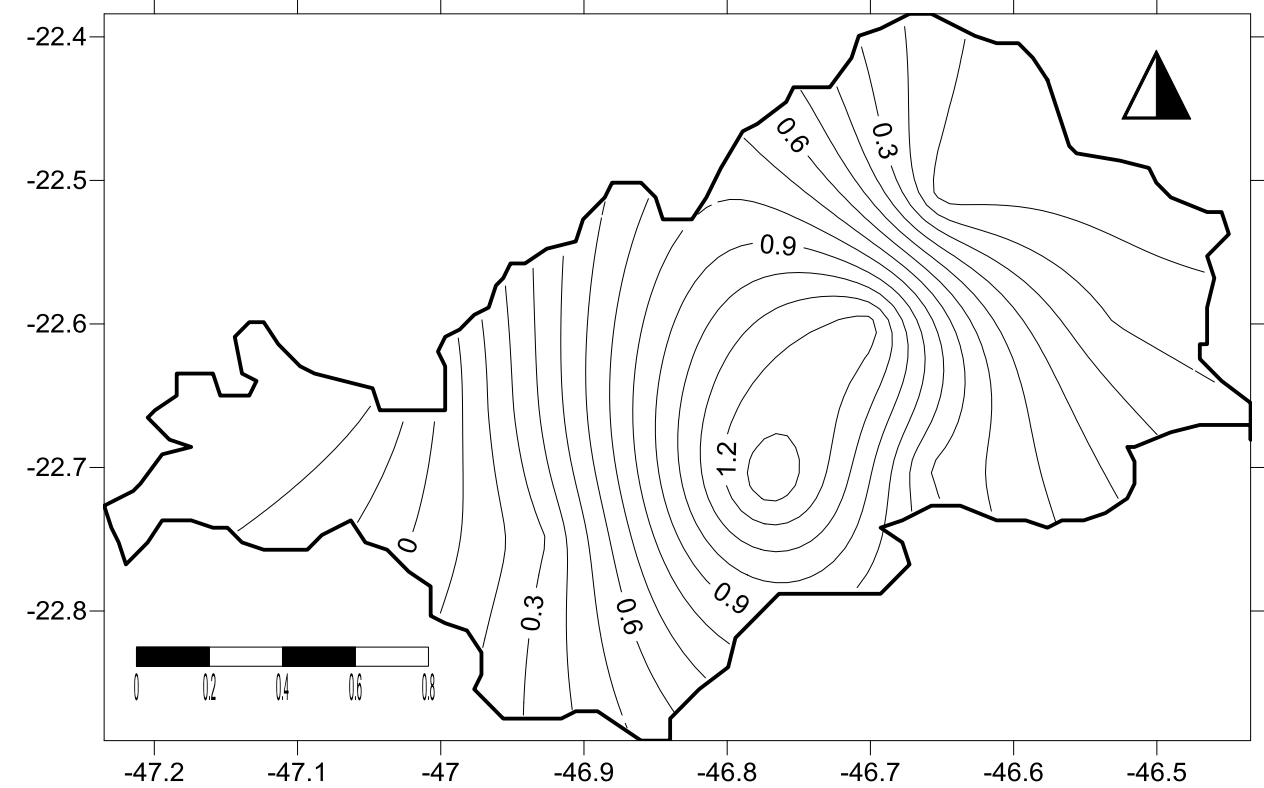

Figura 7: Mapa de distribuição dos valores do SPI, em uma escala de 6 meses, para o Circuito das Águas Paulista, em 2009.

Neste ano, houve a ocorrência do fenômeno El Niño, de fraca intensidade. No Brasil, quando o El Niño ocorre, a variação no volume de chuvas depende de cada região e da intensidade do fenômeno, no entanto a temperatura aumenta na maioria das regiões (Nery, 2013). 
Para uma escala de 12 meses, no ano de 2009, os valores de SPI apresentam-se bem abaixo dos encontrados para a escala de 6 meses (Figura 8).

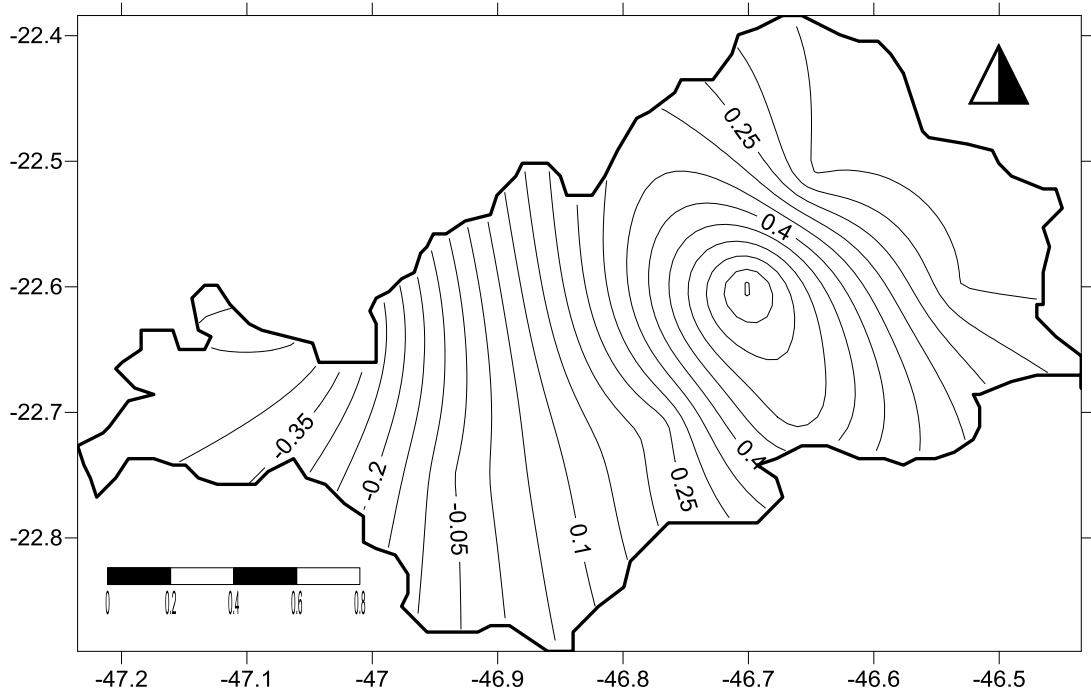

Figura 8: Mapa de distribuição dos valores do SPI, em uma escala de 12 meses, para o Circuito das Águas Paulista, em 2009.

Os valores de SPI encontram-se, em sua maioria, negativos, o que indica uma situação de déficit de precipitação, no entanto devido a alguns valores próximos da normal $(0,4)$ pode-se caracterizar o ano como próximo da normal esperada para região estudada, sem deixar de levar em consideração a grande mudança sofrida em 6 meses de análise por ter se apresentado como um ano extremamente úmido anteriormente.

O ano de 2011, último analisado neste estudo, apresenta-se com um alto nível de déficit hídrico de acordo com a análise dos valores de SPI, para a escala de 6 meses (Figura 9).

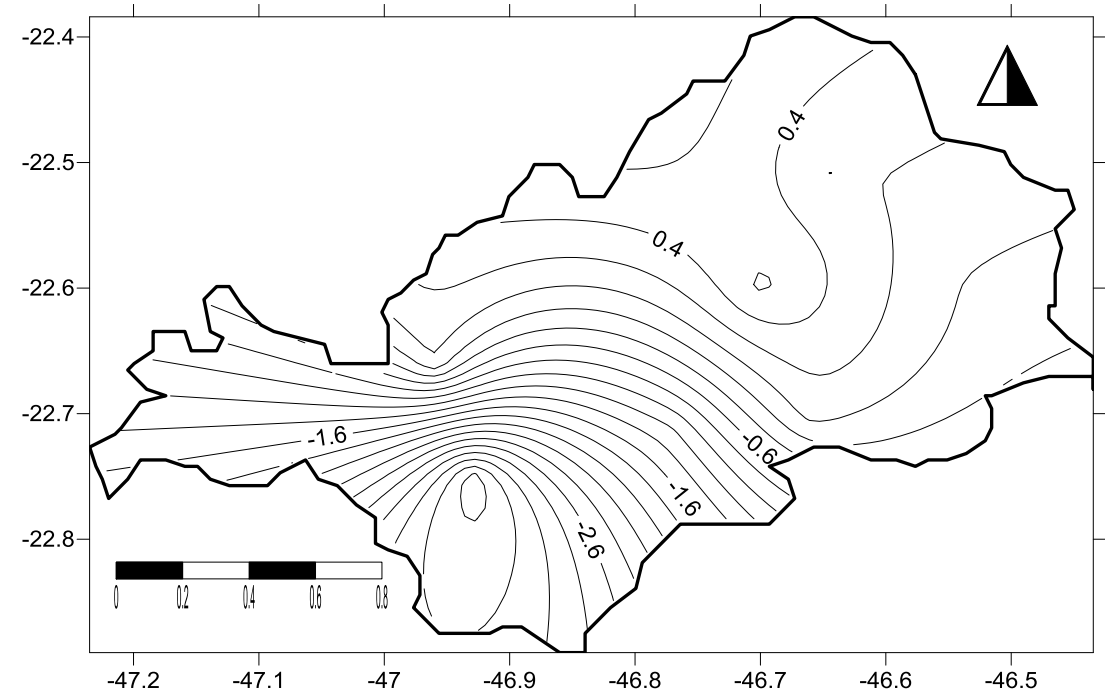

Figura 9: Mapa de distribuição dos valores do SPI, em uma escala de 6 meses, para o Circuito das Águas Paulista, em 2011. 
Os valores de SPI apresentam-se entre 0,4 e -2,6 (Figura 9). Tais valores indicam que na escala de 6 meses de análise, o ano de 2011 oscila de próximo do normal a extremamente seco, indicando, mais uma vez, a variabilidade da precipitação no local e pode ser atribuída à sazonalidade da mesma na região de estudo.

Para 12 meses de escala (Figura 10), os valores de SPI ainda indicam situação de déficit hídrico, no entanto de menor intensidade, ficando concentrados entre 0,2 e $-1,2$, caracterizado como muito seco e não mais extremamente seco. Tal característica indica uma redução no déficit hídrico que o local vinha sofrendo ao longo do ano de 2011.

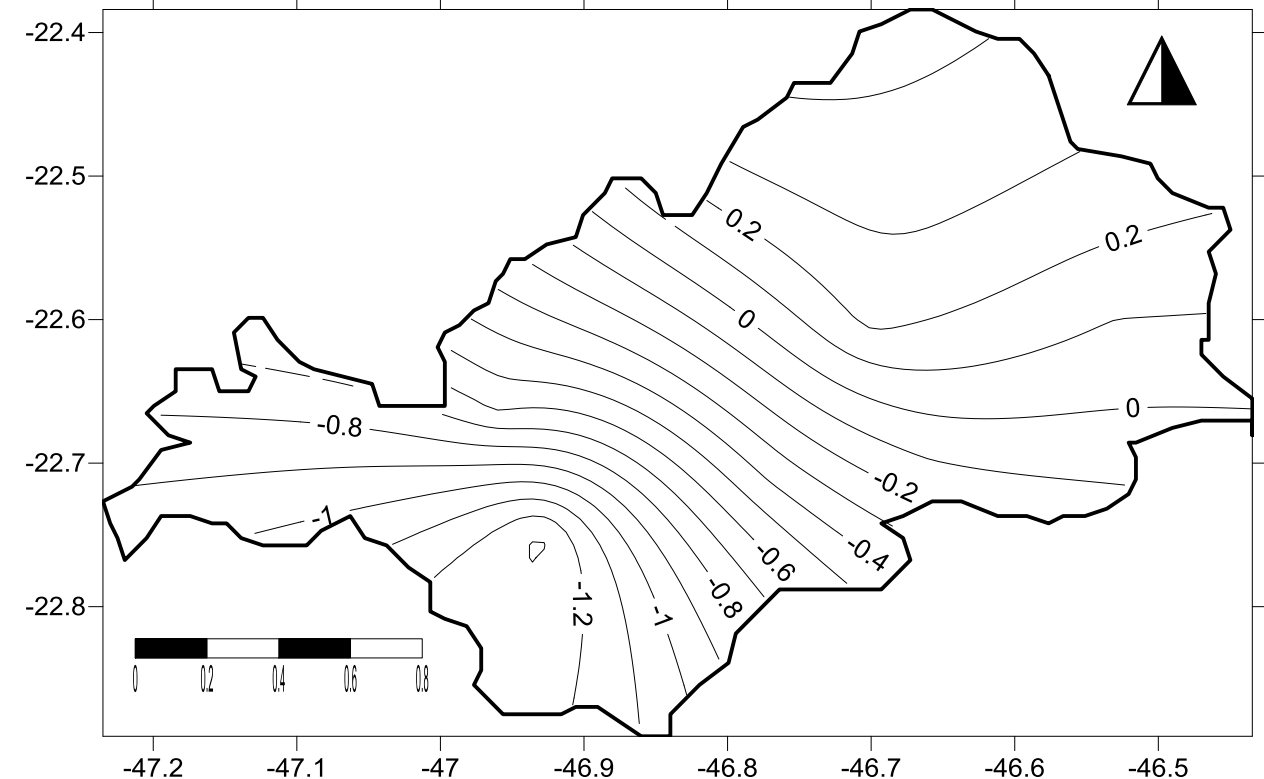

Figura 10: Mapa de distribuição dos valores do SPI, em uma escala de 12 meses, para o Circuito das Águas Paulista, em 2011.

\section{CONCLUSÕES}

O Índice Padronizado de Precipitação é de grande relevância por se tratar de um índice que apresenta a variabilidade da precipitação em qualquer área de estudo, desde que esta apresente quantidade suficiente de estações meteorológicas, bem como, dados consistentes para que se possa obter bons resultados.

No Circuito das Águas Paulista, o regime de chuvas apresenta-se com marcada variabilidade nos anos escolhidos para o estudo, deixando claro a forte influência que sofre de evento ENOS. Os resultados são importantes e mostram a relevância hídrica da área de estudo para o estado de São Paulo, pois trata-se de uma região que na maior parte do ano possui altos índices de umidade devido a ocorrência de precipitação, sendo assim, de grande importância hídrica, consequentemente econômica.

Os municípios de Águas de Lindóia e Socorro são os que apresentam os maiores valores de SPI, indicando umidade extrema na região em quase todos 
os anos, essencialmente em 1983. Os municípios de Pedreira e Jaguariúna são os que apresentaram maior déficit hídrico ao longo do período estudado.

Dessa forma, os resultados do trabalho justificam a caracterização que a região recebe de grande centro hidrotermal, hoteleiro, turístico e também referência na produção e comércio de algumas frutas, malhas e qualidade e distribuição de água na região.

\section{REFERÊNCIAS BIBLIOGRÁFICAS}

ABRAMOWITZ, M.; STEGUN, I. A. Handbook of mathematical functions with formulas, graphs and mathematical tables. Washington: U. S. Department of Commerce, 1046p. 1965.

AGÊNCIA NACIONAL DE ÁGUAS - ANA. Disponível em: www.ana.gov.br. Acesso em: 12 de fev. 2015.

AMARAL, E.; BAPTISTA DA SILVA, J. Periodicidades climáticas. In: SEMINÁRIO INTERNACIONAL SOBRE CLIMATOLOGIA DO HEMISFÉRIO SUL, 1997, Campinas, Anais..., Campinas: Organização Meteorológica Mundial, v. 1, p. 1-7, 1997. 1 CD-ROM.

Centro de Previsão de Tempo e Estudos Climáticos - CPTEC. Disponível em: http://www.cptec.inpe.br/. Acesso em: 16 de fev. 2015.

FERNANDES, D. S.; HEINEMANN, A. B.; PAZ, R. L. F. da; AMORIM, A. de O.; CARDOSO, S. Índices para a quantificação da seca. Santo Antônio de Goiás: Embrapa Arroz e Feijão, 2009. 45p. (Embrapa Arroz e Feijão. Documentos, 244).

FUINI, L. L. Manifestações da governança territorial no Brasil: uma análise do Circuito das Águas Paulista e do Circuito das Malhas do Sul de Minas Gerais. 2010. 191f. Tese (Doutorado em Geografia) - Instituto de Geociências e Ciências Exatas, Universidade Estadual Paulista, 2010.

Instituto Brasileiro de Geografia e Estatística - IBGE. Disponível em: <http://www.ibge.gov.br/> Acesso em: 25 de julho de 2013.

KOUSKY, V. E. Pentada outgoing longwave radiation climatology for the South American sector. Revista Brasileira de Meteorologia, v.3, p.217-231, 1998.

MCKEE, T. B.; DOESKEN, N. J.; KLEIST, J. Drought monitoring with multiple times scales. In: CONFERENCE ON APPIED CLIMATOLOGY, 9., 1995, Boston. Proceedings...Boston: American Meteorological Society, 1995. p.233-236. (Preprints).

MCKEE, T. B.; DOESKEN, N. J.; KLEIST, J. The relationship of drought frequency and duration to the time scales. In: CONFERENCE ON APPLIED CLIMATOLOGY, 8., 1993, Anhaeim, CA. Proceedings. Boston: American Meteorological Society, 1993. p. 179-184. 
NERY, J. T.; MARTINS, M. L. O. F. Variabilidade Interanual: Oscilação Sul- EL NIÑO. Apontamentos, n. 75, 1998.

NERY, J. T.; SILVA, E. S.; CARFAN, A. C. Distribuição da precipitação pluvial no estado de São Paulo. In: VI Simpósio Brasileiro de Climatologia Geográfica, Anais..., Aracajú: Associação Brasileira de Climatologia, Aracajú, 2004.

NERY, J. T.; CARFAN, A. C. Glossário de Termos Técnicos em Meteorologia e Climatologia. Jundiaí, Paco Editorial: 2013, 416p.

POVOA, L. V. (2014). Manual do usuário do pacote precintcon. Laboratório Computacional da Universidade Estadual Paulista, campus de Ourinhos, 2014.

QUADRO, M.F.L.; ABREU, M.L. Estudos de episódios de Zonas de Convergência do Atlântico Sul sobre a América do Sul. In: Congresso Brasileiro de Meteorologia, 8:620-623. Belo Horizonte - MG. Anais II.

SANSIGOLO, C. A. Análise comparativa do desempenho dos Índices de Seca de Palmer (PDSI) e da Precipitação Normalizada (SPI) em Piracicaba, SP (19172001). Revista Brasileira de Climatologia, v.19, n.3, 237-242, 2004.

SCHRÖDER, R. Distribuição e curso anual das precipitações no estado de São Paulo. In: Boletim Técnico do Instituto Agronômico do Estado de São Paulo, vol.15. Campinas, agosto de 1956, nº 18.

Texto submetido à RBClima na data de 17/03/2015 